\title{
The use of drones in the maintenance of photovoltaic fields
}

\author{
Fabrizio Bizzarri ${ }^{1}$, Silvia Nitti $^{2}$, and Gabriele Malgaroli ${ }^{2, *}$ \\ ${ }^{1}$ Solar Innovation and Sustainability, Enel Green Power, Rome, Italy \\ ${ }^{2}$ Politecnico di Torino, Dip. Energia, corso Duca degli Abruzzi 24,10129 Torino, Italy
}

\begin{abstract}
Enel Green Power is an Italian company which realises and manages large photovoltaic (PV) plants around the world. The company is involved in a huge number of research projects and one of them involves the use of drones for PV inspection in order to guarantee the correct operation of the plants. In this paper, the use of drones the maintenance of PV plants is analysed from a technical and economic point of view, as function of plant size. First, the use of drones for thermography and visual inspection is briefly described, then, on the basis of on-field activities, the technical specifications of drones and the procedure for the inspection are defined. The results of a thermal infrared analysis performed on six PV plants are analysed. In particular, the failure rates of PV modules are estimated, describing each failure. Finally, an economic analysis is performed in order to evaluate the competitiveness of drones for PV inspection compared to manual maintenance.
\end{abstract}

\section{Innovation in the maintenance of photovoltaic fields}

Enel Green Power is working on innovation and sustainability in several sectors. In particular, the energy sector is experiencing a phase of robotisation in order to increase the sustainability of processes by making daily operations cheaper and faster.

It is fundamental to limit the operation and maintenance $(\mathrm{O} \& \mathrm{M})$ costs, of large-scale photovoltaic (PV) plants (up to several hundreds of installed megawatts), maintaining good productivity. In recent decades, innovations such as drones, exoskeletons, smart glasses, cleaning and grass cutting machines, have been introduced to improve O\&M activities. Drones can perform tasks such as geographical mapping, the monitoring of construction sites, and precision agriculture [1][2]. The exoskeleton is a passive upperlimb technology that assists the shoulder flexionextension of operators in case of overhead manipulations. The use of smart glasses, by field operators allows communication when PV generators are far from central headquarters, and can receive information while working or repairing a failure. Dust and dirt can dramatically reduce PV module power output [3][4]; thus, cleaning is a fundamental maintenance operation. Obviously, manual cleaning is too expensive in the case of multi-megawatt plants, and thus automated solutions such as robots reduce cleaning time and the use of water. Cleaning is generally performed using rotating brushes that are programmable in terms of rotational speed, and the weight of the robot is reduced, in order to avoid highly concentrated loads on the PV modules. Concentrated loads, such as those involved in walking on the modules [5], can cause microcracks and cracks in the cells with unpredictable reductions in production.

Another maintenance task involves reducing the shadows that activate the bypass diodes of the PV modules. The number of productive PV cells decreases, and the maximum power point tracker (MPPT) inside the DC-AC converter may not be able to work properly [6][7]. In free-standing plants, it is necessary to periodically cut the grass to avoid shadows on the bottom modules. Large PV plants are usually located in remote zones, on uneven terrain and sometimes with some slope. A possible solution is the use of remotecontrolled robots, which cut the grass under the supervision of an operator. A more advanced solution is the use of automatic devices: they memorise the pathway and can repeat it without a supervisor. Obviously, they have to be equipped with hardware and software to avoid exceptional obstacles, and safeguard people, themselves and other assets.

In the present paper, properly selected drones are used to map large-scale PV plants and check for possible defects or hotspots by performing visual inspection and thermal infrared analysis. The economic effectiveness of these devices at the end of the plant lifetime is evaluated as a function of the rated power of PV array.

\section{Innovation in the maintenance of photovoltaic fields}

According to flight architecture, there are two types of unmanned aircraft system (UAS): rotor-based and fixedwing. The first type of drone is small, light and easy to control, while the second devices are faster, can reach higher altitudes and carry heavy loads.

\footnotetext{
Corresponding author: gabriele.malgaroli@polito.it
} 
Drones can currently perform a variety of PV-related tasks. They are generally equipped with cameras for the visual inspection of modules: it is possible to rapidly check the presence of modules with visible defects (e.g., modules with broken front-glass). Drones can also be equipped with thermal infrared cameras. Thermal cameras [8][9] are used to check the presence of abnormal temperatures in modules (hot spots), generally due to cracks in the solar cells or other types of defects. The test is performed during the operation of the plants, mainly around noon, when the temperature of the PV modules is the highest. These cameras are also used to check the presence of dangerous temperatures in other components, such as string boxes, cables and converters. Since 2018, drones have also been equipped with nearinfrared cameras, which are used to perform electroluminescence tests [10]. In this case, the device provides a high quality image of the defects, and information related to their causes. Figure 1 shows an example of a drone performing a visual inspection of a PV plant.

Analyses of visual and thermal infrared images are performed after the inspection using appropriate pattern recognition algorithms [11]. In the future, drones will perform data analysis through pattern recognition and change detection. Predictive methods will be used to monitor the productivity of PV plants, optimising strategic O\&M responses [12].

The main advantages of these devices, with respect to traditional approaches, are the following:

- Efficient, fast, and inexpensive inspection of largescale PV plants;

- Safety and increased accessibility to sites that are difficult to reach or with safety risks for humans, e.g., rooftops;

- Flexible dispatch thanks to their low cost;

- Larger types of data collection at a faster rate;

- Higher accuracy of measurements for rooftop and ground assessments.

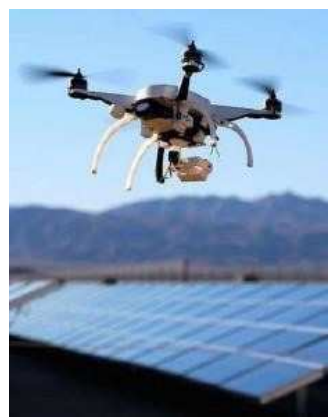

Fig. 1. Drone flying over a PV plant.

\section{Management of the inspections}

The first implementation of drones for visual inspections and thermography analysis was in Enel Green Power North America. This PV plant with a rating power of $179 \mathrm{MW}$ has been inspected with drones analysing about $8 \mathrm{MW} / \mathrm{h}$.

\subsection{Choice of hardware and software}

Drones for the inspection of PV plants do not require high technical specifications because they fly on a $2 \mathrm{D}$ pathway, never exceeding a height of $150 \mathrm{~m}$. For this reason, their associated costs are limited.

The selection of an adequate drone for PV application involves several aspects. A major issue concerning drones is their low flight time. The batteries installed have limited capacity and their replacement may be required during the inspection of a plant, causing delays. Many drones break because they fall down without warning if the batteries are discharged, and this is a potential risk for pilot safety. The weight of the drone cannot be lower than the weight of the camera, it has to withstand gusts of wind of at least $8 \mathrm{~m} / \mathrm{s}$ and compatibility with several types of camera has to be taken into account.

A unique camera with thermal and RGB spectrum or two cameras, one for thermal images detection and one for visual inspection, have to be selected for PV inspections. The first solution is preferred in order to limit the weight on the drone and, thus, allow greater battery life.

It is also important to consider the following aspects:

- Availability of image metadata such as GPS location, relative altitude, gimbal attitude and timestamp;

- Resolution of 640x480 dpi or higher;

- Stabilised gimbal to keep the camera in a stable position despite drone movements;

- Horizontal field of view in order to capture the maximum area in the images.

\subsection{Flight directives}

In this work, visual inspections and thermal infrared analysis of PV plants will be carried out by Enel Green Power operators in fields. The operator will verify the following conditions for the initial pre-flight phase:

- Wind at a maximum speed of $15 \mathrm{mph}(6.7 \mathrm{~m} / \mathrm{s})$;

- Clear or slightly overcast sky, with irradiance $>600$ $\mathrm{W} / \mathrm{m} 2$;

- Relative humidity $\mathrm{RH}<60 \%$;

- Non-existent or low module soiling.

- The pilot will follow the guidelines below for the flight plan:

- The flight boundary line will include an extended area beyond the edges of the solar farm;

- The flight path will be parallel to the rows of the solar farm;

- The flight elevation will be consistently above ground level. Terrain with significant elevation changes may require multiple flights and/or advanced ground control software with terrain following capabilities;

- The gimbal pitch will permit deviations up to $20^{\circ}$ to avoid glare;

- Image capture will be automatic, with a shutter interval set to $2 \mathrm{~s}$;

- The flight speed will not exceed $2.5 \mathrm{~m} / \mathrm{s}$; 
- The front overlap will be $80 \%$ in the direction of flight;

- The side overlap will be $20 \%$ over each pass;

- The image metadata will contain GPS location, relative altitude, gimbal attitude, timestamp;

- There will be a constant camera heading during the inspection despite UAS orientation;

- The images will be saved on a high speed memory card with a UHS-3 rating;

- After the flight, the following last prescriptions are necessary:

- $\quad$ On-site quality check of the entire dataset;

- Re-fly sections of parts of the plant, if some data is missing.

\section{Photovoltaic modules failures}

The cumulative installed PV capacity rapidly grew in the last decade, increasing from $\approx 9.2 \mathrm{GW}$ in 2007 to $\approx 480$ $\mathrm{GW}$ in 2019 [13]. As a consequence, checking the presence of defects on the entire production volume is very long and expensive, therefore, a restricted number of PV modules is usually subject to a manual identification of defects. Moreover, the thickness of wafers for crystalline silicon PV cells decreased from $\approx 0.3 / 0.4 \mathrm{~mm}$ to $\approx 0.2 \mathrm{~mm}$ [14] in order to reduce the wastage of silicon and the manufacturing costs. However, if the wafer is too small, defects such as cracks and microcracks can appear. For these reasons, the maintenance of PV arrays is fundamental in order to detect with fast response defective subarrays and limit the loss of production.

The results of experimental work are analysed in order to define the type of defects that can be detected by thermography and visual inspection. The failures detected by drones are collected in six thermographic reports from plants in North and South America. The average number of damaged modules is less than $2 \%$. The failures are divided into three main categories:

- Cell failure: in many cases, the failure of a cell causes a hot spot. If the temperature increase is high, the entire module must be replaced. There are many other failures that can occur during the first years of life, mainly due to poor quality manufacturing processes [15]). Other phenomena, such as potential induced degradation (PID), overheating of diodes in the junction boxes, and delamination can occur during the life of the plant [16][17][18].

- Protection system issues: this failure category includes cases in which entire strings and arrays are off-line. In this case, there is no damage to the modules, but wires or protective equipment (mainly fuses) are damaged.

- Activated bypass diode and soiling: the activation of the bypass diode can be a consequence of soling or shading. In this case, the production of the cells protected by the diode is lost (generally, PV modules are equipped with three or four diodes). Production can also be reduced due to the incorrect operation of the MPPT [19]. In this case, production is recovered by cleaning the module or the removal of the shadowing obstacle.

\section{MODULE FAULTS}

module thermal anomalies $\square$ protection systtem issues - activated bypass diode

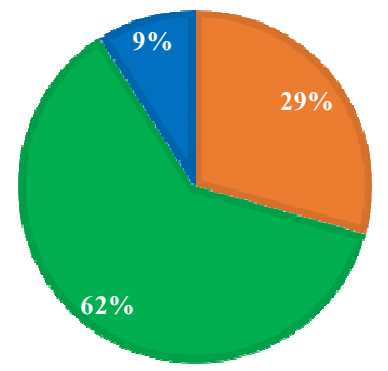

Fig. 2. Frequency for the three categories of failure.

Figure 2 shows the proportions of the total number of failures in the above categories. The most frequent issue is the failure of wires or protective equipment. In this case, the total production of the part of the plant affected by the failure is lost, but the failure is cheap to repair (it does not require module substitution). The other failures comprise $40 \%$ of the total, and in the case of thermal anomalies, the replacement of modules is required.

Visual and thermal inspection permits the detection of failures; but for most of the failures, there is no correlation between the defect and the power loss. In order to calculate power losses, a determination of its current-voltage $(I-V)$ characteristic curve by dynamic methods is necessary [20]. This can be performed with adequate and calibrated measurement systems [21], using capacitive or electronic loads. Thanks to the capacitive load [22], a scan of the entire I-V curve can be easily performed at module, string and array level, up to several hundred kilowatts. In conclusion, the complementary execution of the I-V characterisation of PV generators and the thermal inspection permits defects to be localised and losses to be quantified.

\section{Economic analysis}

The net present value (NPV) is used in budgeting and investment planning to analyse the profitability of an investment or project. For example, it can be used to quantify the cost-effectiveness of the installation of a new PV plant [23], or the replacement of defective modules in existing plants [24]. In this paper, the NPV is used to quantify the cost-effectiveness of the use of drones for thermal inspection, compared to manual thermography. This procedure is repeated for different sizes of PV plants. The formula of the NPV is the following:

$$
N P V=\sum_{t=0}^{t=n} \frac{C_{t}}{(1+r)^{t}}
$$


where $t$ is the number of years, $C_{\mathrm{t}}$ is the cash flow (positive for revenue or negative for costs) at $t^{\text {th }}$ year, and $r$ is the interest rate of the investment (in this case it is assumed equal to $8 \%$ ).

First, the costs have been partitioned into CAPital EXpenditure (CAPEX) and OPerating EXpense (OPEX). CAPEX is the cost of developing or providing durable assets for the product or system, and OPEX is the cost necessary to manage a product, a business or a system. In this study, CAPEX involves two costs:

- Drone, batteries and camera purchase cost;

- Training Enel Green Power operators to become drone pilots.

OPEX are variable costs depending on the plant size. In particular, they involve the following contributions:

- Fixed maintenance costs for hardware;

- $\quad$ Fixed cost for drone replacement every five years;

- Costs concerning survey and the image analysis;

- Maintenance plant cost (mainly module replacement and electrical damage repair and other corrective actions for PV plant).

The economic benefits were investigated, via two terms:

- OPEX reduction passing from manual to automatised inspection that depends on plant size;

- Benefit due to higher production. Using drones, it is possible to perform two inspections per year instead of one, and the average time that the damaged modules spend in the field is halved.

PV plant lifetime is estimated at about 25 years, and so the $N P V$ after 25 years has been calculated as a function of plant size. The $N P V$ increases after 25 years with larger plant size (Fig. 3): the larger the field the higher the gain. Drones are cost-effective solutions for inspections in PV plants with a power rating greater than 50 MW (green columns), but manual methods are preferred for smaller plants (red columns). In this work, the lifetime of the drones is supposed to be five years, therefore, after that time interval, they have to be replaced with new ones.

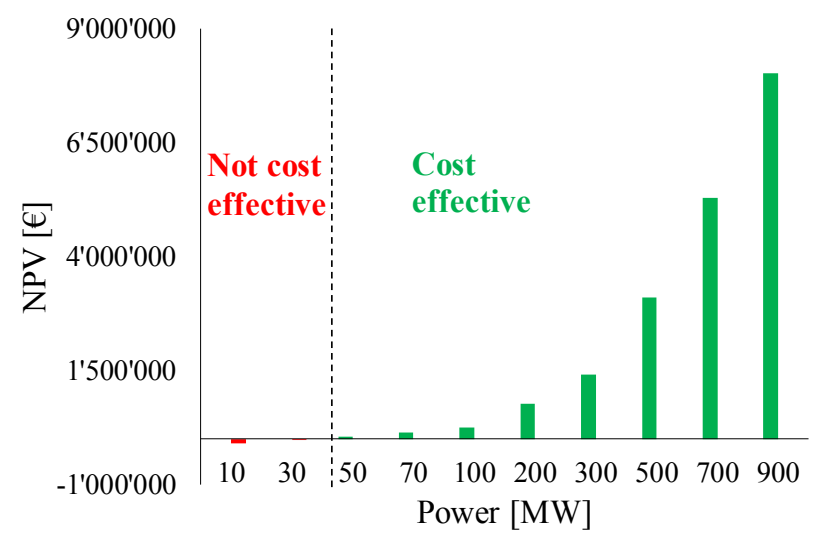

Fig. 3. NPV after 25 years for plants of different sizes.

The Pay Back Time (PBT) is the number of years after which an economic investment is completely balanced by the cumulative incomes. It is positive for PV systems with rated power greater than $50 \mathrm{MW}$ and in Fig. 4, the PBTs due to the utilization of drones for maintenance tasks are reported for these power ratings. The PBT decreases with higher PV rated power and few months are sufficient to have a positive return from the investment with several hundreds of MW installed.

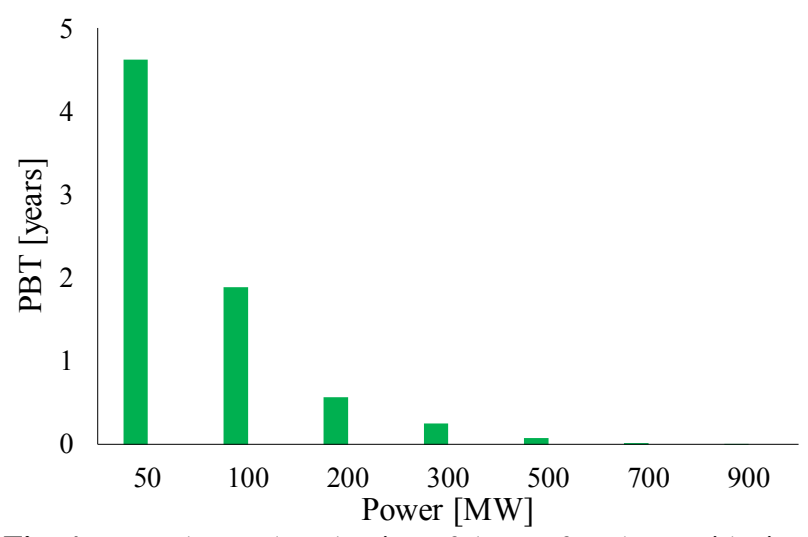

Fig. 4. PBTs due to the adoption of drones for plants with size greater than $50 \mathrm{MW}$.

\section{Conclusions}

Future drones will overcome their current limits, further improving robotisation in PV-related tasks. The current version will be further developed and this drone can fly without human control, because it follows a path inserted in its memory and can be set off remotely. Moreover, it is able to recharge itself thanks to its platform and it is possible to remotely activate, deactivate and even destroy it. It can be used for multiple applications, for example, for surveillance purposes: when someone crosses the perimeter of the field, it raises the alarm and flies to the point of violation, filming the intruder. Obviously, the most interesting use of this drone is data capture: if the company has its own software for the analysis of RGB and infrared images, the drone can fly and take pictures once a week or once a day. Images collected at short time intervals are useful for understanding how the plant degrades based on climate, years of operation, and technology implemented. Data and artificial intelligence are the lines of technological research used to automate the predictive maintenance of large PV plants.

\section{References}

1. S. Dotenco et al., Automatic detection and analysis of photovoltaic modules in aerial infrared imagery, in IEEE Winter Conference on Applications of Computer Vision (WACV), Lake Placid, NY, 1-9 (2016).

2. C. Buerhop, R. Weißmann, H. Scheuerpflug, R. Auer, C. J. Brabec, Quality Control of PV-Modules in the Field Using a Remote-Controlled Drone with an Infrared Camera, in 27th European Photovoltaic Solar Energy Conference and Exhibition (EU PVSEC 2012), 1, 3370-3373 (2012).

3. M. Mostefaoui et al., Importance cleaning of $P V$ modules for grid-connected PV systems in a desert environment, 2018 4th International Conference on 
Optimization and Applications (ICOA), Mohammedia, 1-6 (2018).

4. H. Mei, Z. Shen, C. Zeng, Study on cleaning frequency of grid-connected PV modules based on Related Data Model, 2016 IEEE International Conference on Power and Renewable Energy (ICPRE), Shanghai, 621-624 (2016).

5. F. Spertino, J. Ahmad, A. Ciocia, P. Di Leo, Techniques and Experimental Results for Performance Analysis of Photovoltaic Modules Installed in Buildings, Energy Procedia, 111, 944953 (2017).

6. L. Gao, R. A. Dougal, S. Liu and A. P. Iotova, Parallel-Connected Solar PV System to Address Partial and Rapidly Fluctuating Shadow Conditions, in IEEE Transactions on Industrial Electronics, 56, (5), 1548-1556 (2009).

7. F. Spertino, J. Ahmad, A. Ciocia and P. Di Leo, A technique for tracking the global maximum power point of photovoltaic arrays under partial shading conditions, in IEEE 6th International Symposium on Power Electronics for Distributed Generation Systems (PEDG), Aachen, 1-5 (2015).

8. International Energy Agency, Review on Infrared and Electroluminescence Imaging for PV Field Applications, Report IEA-PVPS T13-10:2018, 2018. [Online]. Available: $\quad \underline{\text { htp://www.iea- }}$ pvps.org/index.php?id=371\&eID=dam_frontend_pu sh\&docID=4318 [Access date: 20 January 2019].

9. G. Schirripa Spagnolo, P. Del Vecchio, G. Makary, D. Papalillo and A. Martocchia, A review of $I R$ thermography applied to $P V$ systems, in 11th International Conference on Environment and Electrical Engineering, 879-884, Venice (2012).

10. F. Spertino, A. Ciocia, P. Di Leo, R. Tommasini, I. Berardone, M. Corrado, A. Infuso, M. Paggi, A power and energy procedure in operating photovoltaic systems to quantify the losses according to the causes, Solar Energy, 118, 313-326 (2015).

11. M. Colaprico, M. F. de Ruvo, G. Leotta, F. Bizzarri, S. Vergura and F. Marino, DUBIO: A Fully Automatic Drones \& Cloud Based Infrared Monitoring System for Large-Scale PV Plants, 2018 IEEE International Conference on Environment and Electrical Engineering and 2018 IEEE Industrial and Commercial Power Systems Europe (EEEIC / I\&CPS Europe), Palermo, pp. 1-5 (2018).

12. Electric Power Research Institute, Utilizing unmanned aircraft systems as a solar photovoltaics operations and maintenance, pp. 4-7.

13. International Renewable Energy Agency, Renewable Capacity Statistics 2019.

14. J. N. Roy and D. N. Bose, Photovoltaic Science and Technology, p. 163 (2018).
15. International Energy Agency, Review of Failures of Photovoltaic Module, 2014, [Online]. Available: http://iea-

pvps.org/fileadmin/dam/intranet/ExCo/IEA-

PVPS T13-

01_2014_Review_of_Failures_of_Photovoltaic_Mo dules_Final.pdf [Access date: 20 January 2019].

16. S. Goranti and G. TamizhMani, Potential induced degradation (PID) study on accelerated stress tested $P V$ modules, 38th IEEE Photovoltaic Specialists Conference, Austin, TX, 2012, pp. 002438-002441.

17. M. Chang et al., The reliability investigation of $P V$ junction box based on $1 G W$ worldwide field database, IEEE 42nd Photovoltaic Specialist Conference (PVSC), New Orleans, pp. 1-4 (2015).

18. N. Park, C. Han, W. Hong and D. Kim, The effect of encapsulant delamination on electrical performance of PV module, 37th IEEE Photovoltaic Specialists Conference, Seattle, WA, pp. 1113-1115 (2011).

19. J. Ahmad, F. Spertino, P. Di Leo and A. Ciocia, A Variable Step Size Perturb and Observe Method Based MPPT for Partially Shaded Photovoltaic Arrays, PCIM Europe 2016; International Exhibition and Conference for Power Electronics, Intelligent Motion, Renewable Energy and Energy Management, Nuremberg, Germany, pp. 1-8 (2016).

20. R. Espino Campos, E. Yoiti Sako, M. Vinicios Gomes dos Reis, M. Gradella Villalva, A Review of the Main Methods to trace the I-V Characteristic Curve of $P V$ Sources, Industry Applications (INDUSCON) 13th IEEE International Conference on, pp. 24-30 (2018).

21. A. Carullo, A. Castellana, A. Vallan, A. Ciocia and F. Spertino, Uncertainty issues in the experimental assessment of degradation rate of power ratings in photovoltaic modules, Measurement, 111, 432-440 (2017).

22. F. Spertino, J. Ahmad, A. Ciocia, P. Di Leo, A. Furtaza and M. Chiaberge, Capacitor charging method for I-V curve tracer and MPPT in photovoltaic systems, Solar Energy, 119, 461-473 (2015).

23. A. Ciocia, V. A. Boicea, A. Dematteis, P. Di Leo, F. Giordano and F. Spertino, $P V$ system integration in buildings: An energy and economic case study, in 10th International Symposium on Advanced Topics in Electrical Engineering (ATEE), Bucharest, pp. 786-790 (2017).

24. A. Z. Bradley and A. A. Meyer, Economic impact of module replacement, 2016 IEEE 43rd Photovoltaic Specialists Conference (PVSC), Portland, OR, pp. 3492-3494 (2016). 